Article

\title{
Enabling Policing to Be Better: Lessons from Two Case Studies in Police Collaboration
}

\author{
Fatema Zaghloul* and Justin Partridge (10 **
}

\begin{abstract}
In the UK, the introduction of austerity measures for public services has intensified the thinking around inter-organizational collaboration between emergency services and other public and/or private sector organizations. Theoretically, while collaborative benefits are held up as beacons that drive organizations to participate in interorganizational arrangements, a high number of such arrangements fail. In this paper, we explored the factors that influenced the collaboration process in the context of developing 'collaborative information infrastructures', from an organizational and collaboration level perspective, via a multiple case study approach. Our findings offer insights into how policymakers and public managers could improve their practices by considering their approach towards, and impact of, these factors when implementing collaborative projects in information technology and information systems.
\end{abstract}

\section{Introduction}

Emergency services such as the ambulance, fire, and police are continuously searching for innovative ways to maximize resources, reduce spending and bureaucracy, and improve service delivery. Over the past three decades, operational reforms and successive legislation (e.g. Civil Contingencies Act 2004 and Policing and Crime Act 2017) have encouraged UK emergency services to collaborate with other public and/or private sector organizations to achieve benefits such as enhanced effectiveness, efficiency, service quality, information integration, and interoperability. A key element in these collaborations is the development of 'collaborative information infrastructures' which can have a significant impact on emergency response and service delivery to the public through facilitating information and intelligence sharing across services, while addressing duplication and silo working within delivery networks.

The public sector context is marked by numerous inter-organizational arrangements ranging from cooperation to collaborations and, in some cases, mergers. It is argued that forming

${ }^{\star}$ Decision Analytics and Risk, Southampton Business School, University of Southampton, Southampton, UK. Email:Fatema.zaghloul@soton.ac.uk

${ }^{\star *}$ Leeds University Business School, University of Leeds, Leeds, UK

Policing, Volume 00, Number 0, pp. 1-17

https://doi.org/10.1093/police/paac018

(C) The Author(s) 2022. Published by Oxford University Press.

This is an Open Access article distributed under the terms of the Creative Commons Attribution License (https://creativecommons.org/licenses/by/4.0/), which permits unrestricted reuse, distribution, and reproduction in any medium, provided the original work is properly cited. 
collaborative arrangements is no longer a luxury, but a necessity and an inescapable feature of future public administration (Gil-Garcia et al., 2019). Despite this, common themes from the literature and practice highlight that evidence of success is difficult to pinpoint and such arrangements face challenges in arriving at benefits and, hence, the majority fail (L'Hoiry, 2021). According to HM Inspector of Constabulary Matt Parr, in response to the latest Inspectorate review (HMICFRS, 2020), 'nationally, forces are spending over a quarter of a billion pounds on collaboration every year ... but too many collaborations are failing'. Failed emergency service collaboration initiatives not only cost those partners involved money, time, and effort, but also affect the taxpayer. Examples of recent failed collaboration invest-

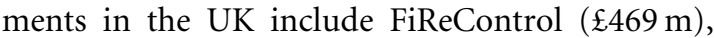
Thames Valley Police tri-force programme $(£ 14 \mathrm{~m})$, and the Warwickshire/West Mercia

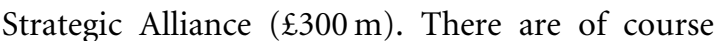
also examples of successful collaborations such as the six examples covered by HMICFRS (2020). Since collaborations, and the ability to maintain them, is an extremely time-consuming and resource-intensive activity, public managers are keen to identify ways to maintain collaborative efforts and evaluate whether their investments are both financially viable and meeting their intended aims/objectives.

There are notable contributions in the literature that sought to better understand where and how inter-organizational collaboration can work in the private and public sector. However, to date, there remains limited understanding of how collaborations in terms of inter-organizational systems (IOS) are developed and maintained in the public safety context. To address this gap, this paper reports on two different UK collaboration arrangements that have been claimed as 'successful': (1) between two police services in England and (2) a regional collaboration between one police service and two fire and rescue services (FRS). Both cases represent the current movement to align information systems (IS) and information technology (IT) among partners but have decided to adopt a different 'collaboration model' based on a number of factors and opportunities at the time of initiation.

The article begins by presenting background and discussion on inter-organizational collaborations in the context of policing and outlines the study setting and approach adopted. We then present the findings from our two case studies, along with a discussion and the practical implications.

\section{Policing context: inter- organizational collaboration}

From a policing perspective, inter-organizational collaboration has been achieved in multiple ways and with a range of organizations, but there is a lack of empirical research on how best to address the paradoxes that challenge successful collaborations (Waardenburg et al., 2020). It is acknowledged that 'one model' does not currently exist; collaboration occurs on an area-by-area basis depending on identified opportunity and mirrors local needs (Parry et al., 2015) and parochial interests, often without consideration of national strategic issues (Higgins et al., 2016). Across England and Wales, collaboration appears to be 'patchy' because of several factors (Kane, 2018), including:

- The timing and nature of funding streams which do not always enable public sector services to collaborate at the same time or to the same degree.

- Inconsistent messages across government departments.

- Local politics which can either stimulate or inhibit collaboration.

- Legacy issues from previous collaborative activity which can influence the appetite for further collaboration.

At present, collaboration has taken many forms, ranging from integrating control rooms or sharing of premises to aligning a specific IS/IT-whether 
with another force and/or other emergency service organizations (HMIC, 2016).

IS/IT underpins most of policing activity, whether in controlling expenditure, supporting intelligence gathering, deploying, and managing resources or providing public access to the police (Ariel, 2019). HMIC revealed the 'poor' state of police ICT, commenting that in too many police forces [ICT] remains quite inadequate and, in some cases, primitive' and 'for too long the police service has lagged far behind the private sector, to the advantage of offenders and the hazard of the public' (HMIC, 2014, pp. 25-26). These IT specific issues are compounded by a lack of knowledge on what constitutes success in police collaborations and deficient performance measurement and limited knowledge sharing (HMICFRS, 2020).

\section{Factors influencing successful outcomes in inter-organizational collaborations}

A focus on technology in isolation will not suffice for collaborative service delivery. Dawes (1996) notes that public benefits from effective information sharing can be limited by organizational and political barriers as much as technical ones. Each emergency services organization comes to a potential collaboration with a history and ideology that influences their technological and information sharing approach (Sanders, 2014). Police forces (PFs) need improved ways to better share information, yet are often uncritical of claims to technological solutions that may not deliver in practice (Sanders and Henderson, 2013). All too often technology research within policing cannot make the link between innovative technologies and outcomes for the public (Lum et al., 2017).

Collaboration is often seen as necessary to enable investment in modern technology and technological solutions are often presented as the way to facilitate joint working between organizations (Dickinson and Sullivan, 2014). However, others have noted that the use of technology within an organization comes with cultural norms and cultural differences can lead to barriers around information sharing and collaboration even where IT solutions are specifically designed to remove these (Parry et al., 2015). Cultural barriers are often under researched and explored (Charman, 2014), but include issues of the rules and norms of conflict resolution, problem and solution definition, power differentials, as well as political and historical baggage. Differing cultures can also be a source of innovation as well as tension (Vangen and Huxham, 2013). Thus, differing IS/IT platforms can be seen as an opportunity for renewal, investment, and innovation; stimulating creative approaches to jointly use organizationally distinct resources to achieve collaborative goals, or as an insurmountable technological and financial barrier to change (Kwon et al., 2009; Vangen and Huxham, 2013) that is not challenged by leaders and budget holders (Meehan et al., 2016). This paper relates two case studies that consider and discuss these persistent IT barriers.

In the public sector context, Kożuch and Sienkiewicz-Małyjurek (2016) conducted a systematic literature review, followed by a hermeneutic process based on a focus group with scholars, to identify factors influencing effective inter-organizational collaboration. They included the factors which create the need to jointly execute the actions as well as determine the progress and outcomes of the collaboration. Factors that determine collaborative activity are associated with requirements that generate the necessity to establish collaboration (e.g. governmental policy, organizational culture, and experience), while factors that influence inter-organizational collaboration refer to issues that affect the efficiency of the collaboration performed (e.g. trust, adaptability to changing work requirements, and communication). These fundamental factors foster effective inter-organizational collaboration. Due to the adoption of the hermeneutic process, these factors were structured by collaboration areas into a 
typology: factors of external environments, factors related to organization characteristics, factors related to people characteristics, relational factors, and instruments of inter-organizational collaboration.

\section{The study}

The objective of this research was to explore the factors influencing the collaboration process between and among PFs in the UK in terms of IS/IT projects. This qualitative research draws upon Activity Theory (AT) as an analytical and theoretical framework (Engeström, 1999). The basic premise of AT is that 'motivation' drives a 'subject' (can be collective or individual), undertaking a particular 'activity', to act upon an 'object' with the main intention of reaching an 'outcome' (Karanasios and Allen, 2014). An activity includes a broader community of stakeholders, is underpinned by social values/judgements, traditional, formal, and informal limits, and may involve the sharing/division of roles and tasks.

Two collaboration models were investigated between February 2018 and May 2019. Each study relied on face-to-face semi-structured interviews with key individuals involved in the collaboration process and the implementation of solutions (including a variety of job focus, experience, and rank), multiple site visits, attending IS management meetings, and document analysis.

Each interview lasted approximately $1.5-2 \mathrm{~h}$. In total, 29 interviews were conducted in the first case study, while 34 interviews were conducted in the second. Access to the data was via the key participants in the case, at senior management levels. Following this, the snowball sampling technique was used which is acknowledged as the most effective method of obtaining access in a 'closed' and political organizational setting such as policing (Allen and Karanasios, 2011). Participants were chosen based on their role and knowledgeability for the study topic.
Each interview was audio-recorded, transcribed, and analysed using a qualitative thematic analysis approach. Based on the theoretical framework used (i.e. AT), a set of initial codes were applied to the data. Additional codes, derived from open coding, were created that added to an understanding of the collaboration process. Finally, 'axial' coding was applied to organize and categorize codes into interpretive concepts depending on the relationship or connection between them (Corbin and Strauss, 2008). This was an iterative process, where codes were continuously rearranged and redefined.

Pseudonyms are used to protect the identity of the organizations and individuals involved, as per the ethical protocol of the study. However, since we are exploring inter-organizational collaborations, we have indicated the perspective of participants from the different organizations.

Case study 1: collaboration involving two PFs Case study 1 (CS1) involved the development of a shared/joint IT department between two PFs in the same region. In 2010, PFs [1] and [2] agreed to collaborate in order to reduce cost and develop a more resilient and robust service provision for a range of fundamental support functions. The arrangement initially comprised two separate IT teams consisting of over 150 IS staff; however, a decision was made early in the process to form a single collaborative unit by making all employees re-apply for positions within the joint department and merge the initial two separate teams.

In terms of financial savings, the collaboration saved:

$\ldots £ 1.4$ million in the first two years...most of that saving was because we've brought two IT departments together, we reduced number of staff from about 150 staff to a single entity which is about 115 so you take about 40 staff out and that's where your big bulk of money come from...and then we made year on 
year savings. . the network itself saved $\mathfrak{1} 400,000$ a year so you're now looking at over 5 years of 2 million worth of savings in revenue on top of the savings in staff. (I2)

\section{CS2: collaboration involving one PF and two FRS}

CS2 involved closing two fire control rooms (FRS1 and FRS2) and co-locating the two teams to a PF control room in the same region in the UK. The collaborative arrangement was a programme built around seven key task areas (KTA) (one of which is IT), rather than a pure IT collaboration. The IT collaboration, in itself, involved aligning technology and IS in the control room (KTA 3), such as telephony, desktop, email systems, infrastructure, and radio Airwave system, between the three partners. The project overview, indicating the seven KTA and governance structure is presented in Fig. 1.

In terms of financial savings, the collaboration calculated efficiency savings of $\mathfrak{£} 1 \mathrm{~m}$ (10\% savings to PF, 50\% FRS1, and 40\% FRS2) in 2016/2017.

\section{Findings and discussion: inter-organizational collaboration in is projects}

\section{Cultural-historical context}

Financial austerity has brought significant pressure among emergency services in the UK (Smith, 2016; Murphy et al., 2019), and, therefore, successive legislation and operational reforms have encouraged emergency services to consider collaboration opportunities to reduce response time to incidents, enhance information sharing and interoperability, and create value for money.

The literature highlights the importance of considering pressures within the environment; the exogenous and endogenous factors that are associated with inter-organizational collaboration in the public sector (Gazley, 2010; Kożuch and Sienkiewicz-Małyjurek, 2016). These factors can potentially result in the establishment and development of a collaborative arrangement or act as an inhibitor to such initiative. It is acknowledged that these factors do not only play a fundamental role in triggering the need for arranging and/or initiating collaborations, but are also found to impact the willingness to continue and the sustainability of the endeavour.

Based on our analysis, we identified two main overarching categories influencing the success of inter-organizational collaborations in this context: (1) organizational (parent) level factors and (2) the collaboration level factors. Table 1 provides a summary of the major categories and sub-category factors that affect inter-organizational collaborations in IS/IT projects.

\section{Organizational factors}

From an organizational perspective, we identified two main factors, namely motivation and reputation management.

Organizational motivation. AT suggests that a subject has 'motivation(s)' towards achieving an

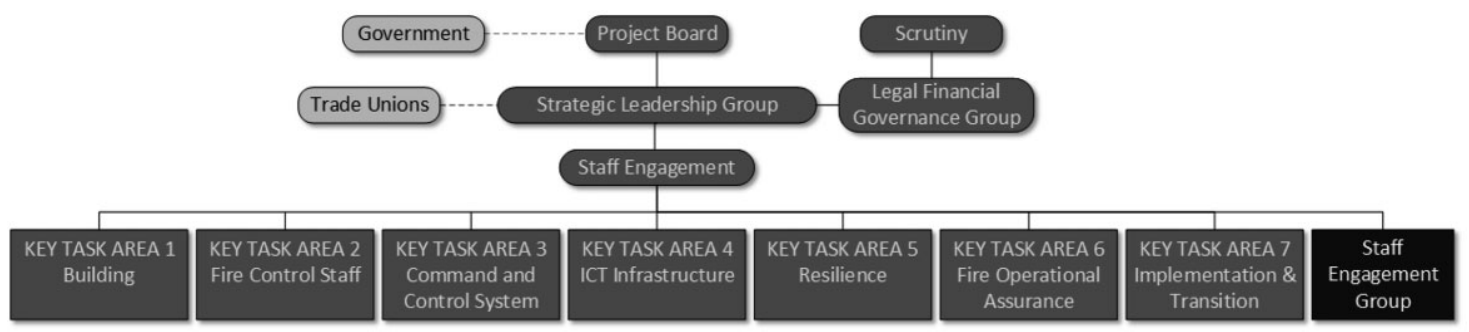

Figure 1: Project governance 
Table 1. Elements influencing the collaboration process activity system

\begin{tabular}{|c|c|c|c|c|}
\hline \multirow{2}{*}{$\begin{array}{l}\text { Organizational } \\
\text { (parent) level }\end{array}$} & \multicolumn{4}{|l|}{ Collaboration level } \\
\hline & $\begin{array}{l}\text { Organisational/ } \\
\text { 'team' }\end{array}$ & Individual characteristics & $\begin{array}{l}\text { Inter-organizational } \\
\text { collaboration }\end{array}$ & Project \\
\hline $\begin{array}{l}\text { Motivation and business } \\
\text { objectives }\end{array}$ & Rules and norms & Experience & Communication & Work overload \\
\hline \multirow[t]{4}{*}{ Reputation management } & Leadership & Formal and informal connections & $\begin{array}{l}\text { Shared vision, } \\
\text { mission, goals }\end{array}$ & \\
\hline & Division of labour & Communication & & \\
\hline & & Willingness to collaborate & & \\
\hline & & Trust & & \\
\hline
\end{tabular}

'object' (Karanasios, 2018). When asked about motivations underlying the collaborative arrangement, a range of responses were obtained. Participants defined motivation as catalysts or drivers which prompted the process. For example,

There were a range of problems; there was a financial problem; there was a resourcing problem; there was a lack of operational integration problem; there was a common problem of obsolescence. (P1, CS1)

It was partly driven because of the austerity programme that the government imposed, particularly on the public sector. (P3, CS1)

Government's agenda was 'collaborate'. In fact, this was pretty much what was driving [organisation] to collaborate. (I4 (FRS), CS2)

In addition, the opportunity to share information, skills, and knowledge, and create a level of resilience, from a resourcing point of view, that could support multiple organizations was also acknowledged:

We were motivated and we are still motivated by the potential opportunities this collaboration had brought and will bring in the future. (I1 (PF1), CS2) ...but in real terms, it's four $\mathrm{X}$ reduced to only two $\mathrm{X}$ between three organisations. So it's the halving of the number of $\mathrm{X}$ we need to provide the same service to the public. (I13 (PF1), CS2)

As a team, what we also did was add another driver saying this can be better, not just better economies of scale, saving money, maximising resources, but we can build a better environment which enables policing to be better. (P6, CS1)

In this research, it became apparent that each organization had its own motivation (or set of motivations) for pursuing a collaborative arrangement, which determined behaviour and effort spent by that organization in the collaboration process. Our analyses revealed that CS1 was driven by existing problems and challenges that needed to be addressed at the time of initiation, while CS2 was mostly driven from the 'business' and heavily influenced by Chief Officers. Drivers mentioned across both case studies include the idea that 'crime knows no boundary' due to the changing nature of crimes, limited funding and resources, and personnel shortages. Motivation was also externally driven; for example, each force is assessed by HMICFRS and needs to fulfil certain objectives depending on their mission and the reviews 
obtained. Generally, motivation to collaborate is directed towards fulfilling these objectives.

With respect to the IOS literature, Lu et al. (2006) revealed that the factors that motivated organizations to pursue IOS initiatives were extremely significant for success. Contrasting with internal IS development and use, IOS motivation was claimed to be more complex. It was essential to have 'strong' motivation to gain commitment from partners, which was mainly based on the long-term strategy of the organization. However, it must be noted that motivation is dynamic and changeable. Overlapping and potentially conflicting motivations (Lompscher, 1999) interact with each other, change with social context over time (Budhathoki et al., 2010) with every individual motivated differently (Ryan and Deci, 2000). This poly-motivational aspect is expressed through competing motivations flowing from individual needs, organizational needs, and collaborative goals.

\section{Organizational reputation management.}

Since collaborations involve multiple organizations, the reputation of each influence, and is influenced by, the collaboration process. For example, reputation management was a concern for one of the PFs involved in CS1:

My own force [name] has only just come out of engagement with the HMIC and the Home Office, which is the naughty step, and we've been in it for two years, so again certainly the previous Chief, but even this Chief, is really careful of stuff that might just drag the attention of the HMIC and the inspector back onto our force.

Historic interactions may need to be addressed in a new collaboration project as prior 'history' creates a perception (or reputation) of other agencies involved in the project. According to Argenti and Druckenmiller (2004), reputation is a 'collective representation of multiple constituencies' images. . built up over time' (p. 369), or the opinions/beliefs held by someone, which ultimately drive behaviour (Brown and Brudney, 2003). Therefore, reputation can be a source of power (French and Raven, 1959). A negative reputation can lead to reactance where individuals react to constructive positive suggestions negatively, while positive reputation can result in a 'Halo' effect (individuals carrying out actions to please others).

From my perspective, [Force 1] had a reputation in [Force 2] of trying to take over everything, and wanting it all done their way. However, when I spoke to people in [Force 2] they said similar things about the reputation of [Force 1] as well. Sometimes we need to challenge the stereotypes that come without dated views of other partners. (P24, CS1)

Reputation management consists of two strands when working in a collaborative project: existent organizational characteristics and perceived professional difference. The former refers to the agencies involved and are based on historical interactions between them. This suggests that analysing the cultural-historical context of an activity is vital. Perceived professional difference refers to general beliefs held regarding a specific profession. Literature specific to information sharing asserts that the difference in professional ethos is a challenge in information sharing and, ultimately, collaborations (Richardson and Asthana, 2005).

\section{Collaboration factors}

This category relates to the factors particularly associated with the collaborative arrangement. We further divide this theme into four main subcategories: 'organizational/team', 'individual characteristics', 'inter-organizational', and 'project'. 


\section{Organizational/team level}

This sub-category refers to the factors related to the organizational or 'team' level of the collaboration project (i.e. CS1-the joint IT department).

Organizational/team leadership. Leadership played a significant role in both case studies:

He's a bit visionary; he's all about strategy and moving things forward. He was appointed as the shared head and then set about in terms of fairly quick time creating the shared service for IS. (P8-CS1)

She's determined it's going to work. (I2 (PF1)-CS2)

It is argued that key personalities can act as enablers or barriers to effective collaboration working. The literature indicates that an organizations' leadership, both at project level and executive level, play a major role in IS/IT projects (Chen et al., 2019) in the public sector, and that a lack of leadership support will potentially result in members doubting the benefits associated with the project and create apathy. It emerged that key personalities could act as barriers to effective partnership working and, hence, a lack of effective leadership can result in such projects suffering from personality-based challenges (Campbell, 2018).

It is noteworthy to mention that not only leadership in terms of an individual(s) leading the project was important, but also the concept of having a 'lead' organization/partner. Although this strategy facilitated decision-making (e.g. harmonization of issues such as pay, annual leave entitlement), it did mean that the non-lead partner slowly became less engaged at a strategic level and only fully engaged if something started to go in an unintended direction. One strategy to solve this could involve ensuring the active participation by partners in the decision-making process.
Organizational/team rules and norms. The literature refers to this element as 'culture', however, to remain in line with AT, we have adopted the term 'rules and norms'. Both collaborative arrangements explored in this study adopted different approaches to manage the differences in rules and norms between partners. CS1 insisted on creating a new culture separate from both parent organizations, creating their unique identity in between two different organizations, while CS2 decided to maintain their own rules and norms and alignment was not achieved, not even between the two FRS. Furthermore, working practices remained the same and, if they differed, negotiation and communication practices were increased until an appropriate decision was reached that pleased all partners.

We created our own culture..., our own identity. (P7, CS1)

The two fire brigades have different terms and conditions. So if you were on maternity leave in this brigade, you'd have more in that brigade, but you're in this brigade, you have more sickness allowances (I5 (PF)—CS2)

Maintaining separate identities, however, created several tensions at multiple levels. For example:

...frustrating because sometimes like Halloween, Bonfire Night, New Year's Eve, we [Police] could do with extra desks, but we can't use them because they are Fire service desks even though they've got shared equipment on them. They'll happily sit on our desks that are free, but we daren't sit on their desks because that's their chairs. They've got green dots on the back of the chair. (I17 (PF))

Furthermore, some participants referred to these as 'domestic' challenges:

They talked about the location in the room. So all of these domestic issues 
holding back collaboration...Some people got to move sometimes to get what they need...So, culturally, there were these challenges. (I19 (PF))

Such instances heightened the importance of communication and grounding the collaborative endeavour on a clear shared vision that is continuously emphasized in order to foster stronger member motivation.

Prior research suggests that agencies whose culture supports flexibility, teamwork, a shared vision, participation in decisions, and consist of an open flow of communication tend to be more valuable in terms of delivering positive outcomes and achieving objectives (Johnson et al., 2003; Kramer et al., 2017; van der Voet and Steijn, 2021). Despite the different management approaches undertaken in both case studies, all these dimensions were evident.

Over decades, the collaboration literature explicitly reports the significance of culture (Bardach, 1998; Huxham and Vangen, 2013; Kożuch and Sienkiewicz-Małyjurek, 2016; Wankhade and Patnaik, 2020). Our case studies reveal an interesting discussion as to whether organizations should align norms and rules or maintain separate norms, and still achieve desired results. Alternatively, should they disregard individual cultures and create a new one built around collaborative working values and practices? In addition, if alignment is to be implemented, should it be done at the start of the collaboration process or during the collaboration? The answer to these questions could depend on the type/form of collaborative arrangement pursued, and/or the partners involved, and/or the extent to which leaders in all organizations are aware of and put in place mitigation to compensate for and respond to grievances raised about the differences.

\section{Organizational/team division of labour.}

Division of labour refers to an organizational structure and/or governance structure in the collaboration literature. One of the themes provided by Huxham and Vangen (2000a,b, 2013) is the structure of partners in the collaboration process; the membership and makeup of the subjects and organizations that participate in the process, which is argued to be a mechanism that facilitates inter-organizational collaboration (Lewis et al., 2010; Curnin and O’Hara, 2019).

Participants mentioned the importance of understanding how each organization operates and the role of key individuals in the structure:

There are a lot of organisational differences and you need to get used to the structures and processes. There were also differences seen in the project boards and the way the police work and the need to identify the individuals who could get things done-like in all organisations there are different types of individuals; those who process and move forward; those who are innovators. Then it's really learning the other organisations and working out the right people to engage with to get that change needed. (P21, CS1)

When we were running our technical design and implementation team, then members of fire service would come in and they would sit in the meetings and we would go through the actions, who is doing what, when, and how. (I1 (PF1), CS2)

And this activity had an extra layer of complexity when multiple organisations are collaborating across professions (i.e. FRS and police):

There was a certain amount of effort to work out who was who, who was equivalent to who. (I2 (FRS1), CS2)

Huxham and Vangen (2013) depict collaboration structure as dynamic, complex, and 
ambiguous. Dynamic, due to the changes in subjects' motivations and goals expected. Similar to any other human endeavour, it is complex because collaboration involves the numerous facets of cultural, social, and political values and norms that each subject and partner brings to the collaboration table. Lastly, the structure is characterized as ambiguous because it may not be self-evident as to what each subject could or can bring to the collaboration, or who should/should not participate. In addition, they claim that deciding how subjects participate and who participates is a key function in the collaboration process.

\section{Individual characteristics}

Several factors related to the characteristics at an individual level were identified to influence interorganizational collaboration and, hence, success.

Individual experience. The experience and history of collaborating, as well as relationships built, appeared to be a key success factor for many participants in both case studies. For example,

I was brought into the [CS2] project because of the past collaboration experiences I had-because I've done project X. (I5 (PF1)-CS2)

Experience is usually divided into two categories: experience of previous collaborative arrangements with partners and experience in general communication with partners. A leaders' previous experience with inter-organizational collaborations helps predict future collaborative efforts (Gazley, 2010), and informal factors such as trust, leadership, and shared values are all part of delivering sustainable collaborations (Bianchi et al., 2021). Collaboration scholars acknowledge the significance of experience, indicating that public managers can become better collaborators and participate more readily in new collaborative endeavours if they have prior collaborative experience (McGuire and Silvia, 2010) as it enables faster development of mutual understanding and trust (Mandell and Steelman, 2003).

Individual informal and formal connections. Informal connections took place during informal physical gatherings/meetings. For example, CS1 consisted of several staff gatherings, while CS2 consisted of a number of staff engagement group meetings. The aim was to build relationships and connections. At a senior level, this enabled further negotiation associated with the collaboration and faster decision-making:

Informally underneath that, and it's one of my sayings 'decisions are rarely taken at a meeting'. Usually if you turn up at a meeting expecting to get a decision you want, you've probably lost. (P2, CS1)

On the other hand, at a staff level and from a senior-staff perspective, this facilitated the creation of relationships between colleagues. For example, a control room supervisor, in CS2, explains:

We now engage people. We don't wait for people to go sick. We find out. [For example], one of my ladies has a grandson who had to have a serious operation in Birmingham...So by supporting her special leave, she's called off to support her daughter... and she's coming back tomorrow, because we've supported her over four days. Whereas in the old way she would have had no choice on Sunday to go sick..., but we've coached her up.

This relationship building also facilitates the creation of an appropriate culture that facilitates the process. Collaborative arrangements require formal communication structures to accomplish goals, as well as informal communication structures to facilitate the generation of new ideas and participation (Wankhade and Patnaik, 2020). 
Individual willingness to collaborate. The willingness and commitment to maintain the collaborative arrangement was a critical factor, despite difficulties and work overload in some instances:

...it meant that only committed people joined the endeavour. (P1, CS1)

It's harder, a lot harder. But we want to be here. (FRS Control staff, CS2)

According to Beech and Huxham (2003) and other scholars (Huxham and Vangen, 2005; Denolf et al., 2015), choosing subjects based on certain characteristics (referred to as member-/ partner-selection) is important for the success of collaborations. Emerson et al. (2012) revealed that the significance of subject membership is the combination of the expertise of each subject, access to resources and information provided by each organization, and commitment. The interviews in this study also demonstrated that subjects needed to be 'personally committed' to the collaboration project; although not always as evident. Commitment to the team, therefore, influences the motivation to contribute resources, ideas, and energy to provide more for the collective good.

'The actions of individuals and projects must be simultaneously regarded as necessary and valuable contributions to the construction of a shared object' (Miettinen, 2005, p. 62), but what happens in collaborations where individual motivations are poorly aligned with the construction of the collaborative shared object? The two strategies observed were firstly to remove the poorly motivated individual from the collaboration. In CS1, there was an explicit acknowledgement that this may require a budget and management time to persuade out and select in for collaborative motivation:

I kept saying to my team 'if you're on the bus, stay on the bus because we are on this journey...it's going to be exciting... If you're not on the bus, then leave early and allow somebody else the opportunity to take your position.' (P16, CS1)

The other strategy was to increase motivation through demonstrating value to the individual. A desire for the object of collaboration can be developed through the individual seeing the value that others attach to them (Miettinen, 2005). Strategic leadership, at both individual and pluralistic levels, (King et al., 2020; Parker et al., 2021) is vital to demonstrate commitment from all organizations involved:

One difference between this collaboration and [another collaboration] was the creation of a highly visible single new entity-one fully supported and committed to publicly by Chief Officers from both forces. They went to the effort of creating a new team, new vision, single location etc, and that sent a really powerful message. (P26, CS1)

So once they believe in themselves that they can do this and that they can work well as a team, then you get the passion that comes with it. So everyone that we've got working for us actually wants to be here. (P7, CS1)

Individual trust. Trust, from both an organizational and individual perspective influenced the collaboration process.

From an organizational perspective:

When something big happens, we [emergency services] put aside our differences and make it work. When we have time to think about collaborating, then people get cold feet, issues of trust and hidden agendas appear. It [collaboration] starts to fall 
apart without a lot of effort. (P26, CS1)

It appeared that transparency was the foundation of building trust:

Absolute transparency on all information ... all information was shared: financial, resourcing, planning, timing. Every aspect of what we did was completely transparent. That helped build trust ... because without trust, nothing works.

This also reduced the likelihood of one organization accusing the other of receiving greater benefits from the collaboration compared to them.

With respect to CS2:

The transparency meant that nobody said we were manipulative. This meant that we could get onto what the real issue was [building the collaborative infrastructure], without having to spend too much time building up the trust again. (I13)

With one supervisor clarifying:

That's the only way it worked ... if you're not transparent, you might as well pack-in. (I11, FRS)

Ensuring that 'nothing failed' and, if something had failed, to effectively communicate that with the senior management team also appeared to facilitate the process:

There was quite a bit of pressure, but a lot of people work very hard to make sure nothing failed and then that buys you more trust. (I8, CS2)

Making sure you're looking after things ... you're not letting things fail even though you're going through a dramatic change .... it buys you more credit with decision makers. They become more lenient in their decision making, which then makes life easier for yourself. Means you can do more and do it faster. (I1, CS1)

Trust, however, seemed to be something that needed reinforcing, especially with the inevitable change in senior management:

When the business are not engaged, they become more sceptical around what we are achieving ... the business now are not bought into where we are and where we'll go-they've taken the 'eye off the ball' and they're focusing on other things. That means we are kind of moving back to that 'untrusted world' that we came from. (I4, CS1)

From an individual perspective, trust was developed during staff engagement meetings and staff gatherings.

Trust is one of the most studied themes in the field of inter-organizational collaboration and contributes to improving the level and quality of cooperation between agencies, hence reducing conflicts, lowering transactional and governance cost, facilitating knowledge exchange and learning, and increasing partner predictability (Wankhade and Patnaik, 2019).

Trust manifests itself in dependable information sharing, predictable and consistent actions of partners, and personal attributes of collaborators (Bardach, 1998; Huxham and Vangen, 2005, 2013; Agranoff, 2007; McGuire and Silvia, 2010). Drake et al. (2004) assert that if people do not trust one another, then they are less inclined to freely collaborate and share information, 'even information that may be relevant and necessary to the successful operation of the organization as a whole' (p. 69), a finding supporting those of Allen et al. (2000). Furthermore, it is claimed that if trust is not available at organizational and individual levels, then the collaboration will not occur, or occur as effectively as if it was present. 
Scholars argue that sufficient trust is required to initiate cooperation, as well as a 'sufficiently successful outcome to reinforce trusting attitudes and underpin substantial and subsequent collaborative activity' (Hudson et al., 1999, p. 248). Over time, this should help develop 'collaborative sustainability' (Cropper, 1996) — a behavioural quality signifying 'future' continuity, persistence, and viability.

\section{Inter-organizational level}

These are elements that are associated with the collaboration journey/process (i.e. not the usual collaboration between two or more organizations but between one team and two locations [i.e. CS1] or one location and two or more teams [CS2]). The interviews revealed the significance of two fundamental factors throughout the collaboration project activity system: communication and having a shared vision.

\section{Inter-organizational communication.}

Communication took place regularly in both case studies and simple tools were adopted. Frequent communication, via three main communication channels (email, Skype, meetings), provided two main purposes throughout the project:(1) keeping stakeholders informed and (2) engaging with stakeholders in order to make and/or reach decisions.

'Stakeholders' here refer to senior level management and actors involved (i.e. suppliers, individuals in other teams, and departments). A two-way communication process (i.e. upward and downward) was observed to be crucial:

Our staff tell us how we can make things right...having staff challenge every decision we make because they'll come up with the gems that make it a better place to work ... we get the best results because they are the experts and they are doing the job day in, day out. (KTA 3 LeadCS2)
A recurring theme in the collaboration literature is the significance of both written and oral communication and the ability to listen to other organizations and members (McGuire, 2006; Huxham and Vangen, 2005, 2013; Kramer et al., 2017). Furthermore, the IOS literature claim the importance of effectively communicating formally and informally with staff at all participating levels and departments (Finney and Corbett, 2007; Denolf et al., 2015). The empirical evidence revealed that communication was frequently undertaken with subjects, in order to define processes, create a collective identity, build trust, and construct relationships around a shared understanding. Communication was also critical when re-instating the motivation underlying the collaborative arrangements.

Inter-organizational shared vision, mission, and goal. Developing a shared vision and common understanding communicated to all members, not only at the start of the collaboration endeavour, but also throughout the process is what differentiated 'successful' collaborations and 'unsuccessful'/ 'failed' collaborations. For example, with respect to CS1, reference was made to the HR collaboration between the same two forces and how it 'failed':

... in some of the other areas that we were looking at, HR, because in reality there was no shared vision. (P16)

...Get people working to the same ideas and want to see it succeed and it'll succeed. (P3)

One participant clarified that a clear vision must be incorporated in the strategy:

What saved me a number of times, particularly as individuals at the top changed, was that the strategy didn't. I still carry around with me the strategy [in 2018] that we wrote back in 2012...it's still relevant...it's like a blueprint. (P3) 
He further explained that when there is a change in Chief Officers and they start to 'question' approaches undertaken, then:

I take out the strategy and give them the same 10-15 min presentation that re-aligns their thinking to the journey they just joined.

A similar approach was implemented and stressed in CS2:

We created a shared vision, and we were engaged through the process. So, everyone knew what was happening and where we'll be going ... that needed to be clear at the start and even now [during the process]. (I8, FRS)

The significance of developing a shared vision or goal among subjects/partners in collaborative arrangements has been noted extensively in the collaboration literature, and mentioned sporadically in the IS literature concerning IOS projects (Denolf et al., 2015; Kurnia et al., 2019). It involves creating an understanding of why delivering the project 'together' is better than pursuing it 'alone', that is continuously emphasized throughout the process (Ospina and Saz-Carranza, 2010). A shared goal is the means to develop a sense of commitment to members of a team, create the shared idea of the future, and establish the guiding rules and norms in order to achieve the vision. According to Chrislip (2002), the notion of a shared goal as a future created over time, with attributes of member alignment and inspiration, should be asserted. This goal needs to be sufficiently compelling that members will continue to pursue it despite challenges and barriers.

\section{Project level}

Project work overload. Work overload occurred during the collaboration process, but more frequently when systems were near to the 'going live' stage.

...I'm overworked sometimes. (SA

Team Staff-CS1)

Staff indicated that in some instances they were 'overworked', yet realized that this was inevitable due to the cultural-historical context (i.e. reduction in staff and monetary challenges) and were willing to pursue the collaborations as demand fluctuates, suggesting this element has strong connections with motivation at an individual level.

It was revealed that subjects handled this very effectively even if they had to 'stay over hours to complete the tasks in hand' (Staff-CS1). This was significantly associated with the motivation of employees as it was indicated that individuals were aware of this factor, yet they were 'determined to finish what they had to' (Staff-CS2).

When reviewing the collaboration literature, specifically the factors that influence the collaboration process in various contexts, work overload did not seem to be noted extensively, but had greater prevalence in the IS literature associated with the implementation of information sharing projects across multiple cross-sector organizations and systems development. With respect to a study conducted on health and social service collaborations, the 'competing demands on already overworked staff (Johnson et al., 2003, p. 80) contributed to collaborations being unsuccessful.

\section{Conclusion and future research}

The notion of inter-organizational collaboration has received increasing attention, particularly in solving complex problems that are beyond the capabilities and capacities of a single organization. However, both practice and the literature illustrate the difficulty in achieving successful outcomes from collaborative efforts and many initiatives fail at the expense of the organization and the taxpayer. This research explored two 'successful' case studies in the context of the UK emergency 
services and highlighted several elements influencing the management of IT/IS collaboration projects, via the lens of AT. The findings revealed that the elements were evident across both cases, but the major difference was in relation to how senior leaders decided to manage them. The approach and strategies adopted may depend on the collaboration model pursued and/or the organizations involved in the endeavour.

Our understanding could be developed further if other collaboration arrangements are investigated. It would be interesting to explore IS collaboration initiatives that have discontinued/'failed'; enabling the identification of factors that contribute to success, those that influence senior leaders' decisions to participate or not in collaborative endeavours, and to improve understanding of key decision-making in collaborations more widely. Since this research focused on the organizational and collaboration levels, it would be insightful to understand how the perspective of the individual affects the decision-making and ongoing management of collaborations, particularly where there are contradictions and conflicts between individual, organizational, and collaborative motivation.

\section{Acknowledgements}

The authors would like to thank the police forces and fire and rescue services that allowed us access for their support and cooperation. They would also like to thank the anonymous reviewers of this article for their insightful comments, which added to the quality of the paper.

\section{References}

Agranoff, R. (2007). Managing within Networks: Adding Value to Public Organizations. Washington (DC): Georgetown University Press.

Allen, D., and Karanasios, S. (2011). 'Critical Factors and Patterns in the Innovation Process'. Policing 5(1): 87-97.

Allen, D. K., Colligan, D., Finnie, A., and Kern, T. (2000). 'Trust, Power and Interorganizational Information
Systems: The Case of the Electronic Trading Community TransLease.' Information Systems Journal 10(1): $21-40$.

Argenti, P. A. and Druckenmiller, B. (2004). 'Reputation and the Corporate Brand.' Corporate Reputation Review 6(4): 368-374.

Ariel, B. (2019). 'Advocate: Technology in Policing.' In Weisburd, D. and Braga, A. A. (eds) Police Innovation: Contrasting Perspectives. 2nd edn. Cambridge: Cambridge University Press, pp. 485-516.

Bardach, E. (1998). Getting Agencies to Work Together the Practice and Theory of Managerial Craftsmanship. Washington (DC): Brookings Institution Press.

Beech, N. and Huxham, C. (2003). 'Cycles of Identity Formation in Interorganizational Collaborations.' International Studies of Management \& Organization 33(3): $28-52$.

Bianchi, C., Nasi, G., and Rivenbark, W. C. (2021). 'Implementing Collaborative Governance: Models, Experiences, and Challenges.' Public Management Review 23(11): 1581-1589.

Brown, M. M. and Brudney, J. L. (2003). 'Learning Organizations in the Public Sector? A Study of Police Agencies Employing Information and Technology to Advance Knowledge.' Public Administrative Review 63(1): 30-43.

Budhathoki, N., Nedovic-Budic, Z., and Bruce, B. (2010). 'An Interdisciplinary Frame for Understanding Volunteered Geographic Information.' Geomatica 64: 11-26.

Campbell, J. W. (2018). 'Efficiency, Incentives, and Transformational Leadership: Understanding Collaboration Preferences in the Public Sector.' Public Performance \& Management Review 41(2): 277-299.

Charman, S. (2014). 'Blue Light Communities: Cultural Interoperability and Shared Learning between Ambulance Staff and Police Officers in Emergency Response.' Policing \& Society 24(1): 102-119.

Chen, Y.-C., Hu, L.-T., Tseng, K.-C., Juang, W.-J., and Chang, C.-K. (2019). 'Cross-Boundary e-Government Systems: Determinants of Performance.' Government Information Quarterly 36(3): 449-459.

Chrislip, D. D. (2002). The Collaborative Leadership Fieldbook. Vol. 255. John Wiley \& Sons.

Corbin, J. and Strauss, A. (2008). Basics of Qualitative Research. (3rd ed.). https://doi.org/10.4135/9781452230153.

Cropper, S. (1996). 'Collaborative Working and the Issue of Sustainability.' Creating Collaborative Advantage 80-100.

Curnin, S. and O'Hara, D. (2019). 'Nonprofit and Public Sector Interorganizational Collaboration in Disaster Recovery: Lessons from the Field.' Nonprofit Management and Leadership 30(2): 277-297.

Dawes, S. S. (1996). 'Interagency Information Sharing: Expected Benefits, Manageable Risks.' Journal of Policy Analysis and Management 15(3): 377-394. 
Denolf, J. M., Trienekens, J. H., Wognum, P. N., van der Vorst, J. G., and Omta, S. O. (2015). 'Towards a Framework of Critical Success Factors for Implementing Supply Chain Information Systems.' Computers in Industry 68: $16-26$.

Dickinson, H. and Sullivan, H. (2014). 'Towards a General Theory of Collaborative Performance: The Importance of Efficacy and Agency.' Public Administration 92(1): 161-177.

Drake, D. B., Steckler, N. A., and Koch, M. J. (2004). 'Information Sharing in and across Government Agencies: The Role and Influence of Scientist, Politician, and Bureaucrat Subcultures.' Social Science Computer Review 22(1): 67-84.

Emerson, K., Nabatchi, T., and Balogh, S. (2012). 'An Integrative Framework for Collaborative Governance.' Journal of Public Administration Research and Theory 22(1): $1-29$.

Engeström, Y. (1999). 'Expansive Visibilization of Work: An Activity Theoretic Perspective.' Computer Supported Cooperative Work 8(1/2): 66-92.

Finney, S. and Corbett, M. (2007). 'ERP Implementation: A Compilation and Analysis of Critical Success Factors.' Business Process Management Journal 13(3): 329-347.

Gazley, B. (2010). 'Linking Collaborative Capacity to Performance Measurement in Government-Nonprofit Partnerships.' Nonprofit and Voluntary Sector Quarterly 39(4): 653-673.

Gil-Garcia, J. R., Guler, A., Pardo, T. A., and Burke, G. B. (2019). 'Characterizing the Importance of Clarity of Roles and Responsibilities in Government Inter-Organizational Collaboration and Information Sharing Initiatives.' Government Information Quarterly 36(4): 101393.

Higgins, A., Hales, G., and Muir, R. (2016). The Governance of Supra-Force Specialist Policing Capabilities: A Review by the Police Foundation. The Police Foundation. London.

HMIC. (2014). The Annual Assessment of Policing in England and Wales 2012/13. London: HMSO.

-. (2016). PEEL: Police Efficiency 2016: A National Overview. London: HMSO.

HMICFRS. (2020). PEEL Spotlight Report: The Hard Yards-Police to Police Collaboration. London: Her Majesty's Inspectorate of Constabulary and Fire \& Rescue Services.

Hudson, B., Hardy, B., Henwood, M., and Wistow, G. (1999). 'In Pursuit of Inter-Agency Collaboration in the Public Sector: What Is the Contribution of Theory and Research?' Public Management: An International Journal of Research and Theory 1(2): 235-260.

Huxham, C. and Vangen, S. (2000a). 'Ambiguity, Complexity and Dynamics in the Membership of Collaboration.' Human Relations 53(6): 771-806.
Huxham, C. and Vangen, S. (2000b). 'Leadership in the Shaping and Implementation of Collaboration Agendas: How Things Happen in a (Not Quite) Joined-up World.' Academy of Management Journal 43(6): 1159-1175.

Huxham, C. and Vangen, S. (2005). Managing to Collaborate: The Theory and Practice of Collaborative Advantage. London: Routledge.

Huxham, C. and Vangen, S. (2013). Managing to Collaborate: The Theory and Practice of Collaborative Advantage. Routledge.

Johnson, P., Wistow, G., Schulz, R., and Hardy, B. (2003). 'Interagency and Interprofessional Collaboration in Community Care: The Interdependence of Structures and Values.' Journal of Interprofessional Care 17(1): 70-83.

Kane, E. (2018). 'Chapter 6: Collaboration in the Emergency Services.' In Murphy, P. and Greenhalgh, K. (eds.), Fire and Rescue Services Leadership and Management Perspectives. Cham: Springer, 77-91.

Karanasios, S. and Allen, D. (2014). 'Mobile Technology in Mobile Work: Contradictions and Congruencies in Activity Systems.' European Journal of Information Systems 23(5): 529-542.

Karanasios, S. (2018). 'Toward a Unified View of Technology and Activity: The Contribution of Activity Theory to Information Systems Research.' Information Technology and People 31(1): 134-155.

King, M., Wilson, R., and Wilson, S. (2020). Organisational Effectiveness and Collaboration across the System: Literature Review Summary. London: HMSO.

Kożuch, B. and Sienkiewicz-Małyjurek, K. (2016). 'Factors of Effective Inter-Organizational Collaboration: A Framework for Public Management.' Transylvanian Review of Administrative Sciences 12(47): 97-115.

Kramer, M. W., Hoelscher, C. S., Nguyen, C., Day, E. A., and Cooper, O. D. (2017). 'Structuration Processes in an Interagency Collaboration: Enabling and Constraining Participation and Efficiency.' Journal of Applied Communication Research 45(4): 429-444.

Kurnia, S., Parker, C., Ali, M., and Karnali, R. (2019). 'The Impact of Multilevel Contextual Factors on is Adoption at the Inter-Organizational Level' . Communications of the Association for Information Systems 44(1): 421-459.

Kwon, H., Pardo, T. A., and Burke, G. B. (2009). 'Interorganizational Collaboration and Community Building for the Preservation of State Government Digital Information: Lessons from NDIIPP State Partnership Initiative.' Government Information Quarterly 26(1): 186-192.

L'Hoiry, X. (2021). 'It's like I'm Having an Affair': Cross-Force Police Collaborations as Complex Problems.' Policing: A Journal of Policy and Practice 15(2): 1095-1109. 
Lewis, L., Isbell, M. G., and Koschmann, M. (2010). 'Collaborative Tensions: Practitioners' Experiences of Interorganizational Relationships.' Communication Monographs 77(4): 460-479.

Lompscher, J. (1999). 'Motivation and Activity.' European Journal of Psychology of Education 14(1): 11-22.

Lu, X. H., Huang, L. H., and Heng, M. S. (2006). 'Critical Success Factors of Inter-Organizational Information Systems - a Case Study of Cisco and Xiao Tong in China.' Information \& Management 43(3): 395-408.

Lum, C., Koper, C. S., and Willis, J. (2017). 'Understanding the Limits of Technology's Impact on Police Effectiveness.' Police Quarterly 20(2): 135-163.

Mandell, M. P. and Steelman, T. (2003). 'Understanding What Can Be Accomplished through Interorganisational Innovations.' Public Management Review 5(2): 197-224.

McGuire, M. (2006). 'Collaborative Public Management: Assessing What We Know and How We Know It.' Public Administration Review 66(s1): 33-43.

McGuire, M. and Silvia, C. (2010). 'The Effect of Problem Severity, Managerial and Organizational Capacity, and Agency Structure on Intergovernmental Collaboration: Evidence from Local Emergency Management.' Public Administration Review 70(2): 279-288.

Meehan, J., Ludbrook, M. N., and Mason, C. J. (2016). 'Collaborative Public Procurement: Institutional Explanations of Legitimised Resistance.' Journal of Purchasing and Supply Management 22(3): 160-170.

Miettinen, R. (2005). 'Object of Activity and Individual Motivation.' Mind, Culture and Activity 12(1): 52-69.

Murphy, P., Wankhade, P., and Lakoma, K. (2019). 'The Strategic and Operational Landscape of Emergency Services in the UK.' International Journal of Emergency Services 9(1): 69-88.

Ospina, S. M. and Saz-Carranza, A. (2010). 'Paradox and Collaboration in Network Management.' Administration and Society 42(4): 404-440.

Parker, S., Hartley, J., Beashel, J., and Vo, Q. (2021). 'Leading for Public Value in Multi-Agency Collaboration.' Public Policy and Administration 095207672199949.

Parry, J., Kane, E., Martin, D., and Bandyopadhyay, S. (2015). Research into Emergency Services Collaboration. Emergency Services Collaboration Working Group.
Richardson, S. and Asthana, S. (2005). 'Inter-Agency Information Sharing in Health and Social Care Services: The Role of Professional Culture.' British Journal of Social Work 36(4): 657-669.

Ryan, R. M. and Deci, E. L. (2000). 'Intrinsic and Extrinsic Motivations: Classic Definitions and New Directions.' Contemporary Educational Psychology 25(1): 54-67.

Sanders, C. B. and Henderson, S. (2013). 'Police "Empires" and Information Technologies: Uncovering Material and Organisational Barriers to Information Sharing in Canadian Police Services.' Policing and Society 23(2): 243-260.

Sanders, C. B. (2014). 'Need to Know vs. Need to Share: Information Technology and the Intersecting Work of Police, Fire and Paramedics.' Information, Communication \& Society: Communication and Information Technologies Section (ASA) 17(4): 463-475.

Smith, R. (2016). 'Policing in Austerity: Time to Go Lean?.' International Journal of Emergency Services 5(2): 174-183.

van der Voet, J. and Steijn, B. (2021). 'Team Innovation through Collaboration: How Visionary Leadership Spurs Innovation via Team Cohesion.' Public Management Review 23(9): 1275-1294.

Vangen, S. and Huxham, C. (2013). 'Building and Using the Theory of Collaborative Advantage.' In: Keast, R., Mandell, M. P., and Agranoff, R. (eds), Network Theory in the Public Sector: Building New Theoretical Frameworks. New York: Taylor and Francis, pp. 51-67.

Waardenburg, M., Groenleer, M., Jong, Jd., and Keijser, B. M. J. (2020). 'Paradoxes of Collaborative Governance: Investigating the Real-Life Dynamics of Multiagency Collaborations Using a Quasi-Experimental Action-Research Approach.' Public Management Review 22(3): 386-407.

Wankhade, P. and Patnaik, S. (2019). 'Trust in the Context of Emergency Service Collaborations.' In Wankhade, P., and Patnaik, S. (eds.), Collaboration and Governance in the Emergency Services. Cham: Palgrave Pivot. pp. 65-82.

Wankhade, P. and Patnaik, S. (2020). Collaboration and Governance in the Emergency Services. Issues, Opportunities and Challenges. Palgrave Macmillan. 